\title{
Analysis of common bean expressed sequence tags identifies sulfur metabolic pathways active in seed and sulfur-rich proteins highly expressed in the absence of phaseolin and major lectins
}

\author{
Fuqiang Yin ${ }^{1,2}$, Agnieszka Pajak ${ }^{2}$, Ralph Chapman ${ }^{2}$, Andrew Sharpe ${ }^{3}$, Shangzhi Huang ${ }^{1}$ and Frédéric Marsolais ${ }^{2,4^{*}}$
}

\begin{abstract}
Background: A deficiency in phaseolin and phytohemagglutinin is associated with a near doubling of sulfur amino acid content in genetically related lines of common bean (Phaseolus vulgaris), particularly cysteine, elevated by $70 \%$, and methionine, elevated by $10 \%$. This mostly takes place at the expense of an abundant non-protein amino acid, S-methyl-cysteine. The deficiency in phaseolin and phytohemagglutinin is mainly compensated by increased levels of the $11 \mathrm{~S}$ globulin legumin and residual lectins. Legumin, albumin-2, defensin and albumin-1 were previously identified as contributing to the increased sulfur amino acid content in the mutant line, on the basis of similarity to proteins from other legumes.

Results: Profiling of free amino acid in developing seeds of the BAT93 reference genotype revealed a biphasic accumulation of gamma-glutamyl-S-methyl-cysteine, the main soluble form of S-methyl-cysteine, with a lag phase occurring during storage protein accumulation. A collection of 30,147 expressed sequence tags (ESTs) was generated from four developmental stages, corresponding to distinct phases of gamma-glutamyl-S-methyl-cysteine accumulation, and covering the transitions to reserve accumulation and dessication. Analysis of gene ontology categories indicated the occurrence of multiple sulfur metabolic pathways, including all enzymatic activities responsible for sulfate assimilation, de novo cysteine and methionine biosynthesis. Integration of genomic and proteomic data enabled the identification and isolation of cDNAs coding for legumin, albumin-2, defensin D1 and albumin-1A and -B induced in the absence of phaseolin and phytohemagglutinin. Their deduced amino acid sequences have a higher content of cysteine than methionine, providing an explanation for the preferential increase of cysteine in the mutant line.

Conclusion: The EST collection provides a foundation to further investigate sulfur metabolism and the differential accumulation of sulfur amino acids in seed of common bean. Identification of sulfur-rich proteins whose levels are elevated in seed lacking phaseolin and phytohemagglutinin and sulfur metabolic genes may assist the improvement of protein quality.
\end{abstract}

\section{Background}

Common bean (Phaseolus vulgaris) is the most important leguminous food crop grown for dry seed worldwide, both in acreage and yield. Historically, this species has been an important model for the study of seed storage proteins [1]. In commercial cultivars, the $7 \mathrm{~S}$ globulin

\footnotetext{
* Correspondence: Frederic.Marsolais@agr.gc.ca

${ }^{2}$ Agriculture and Agri-Food Canada, Southern Crop Protection and Food

Research Centre, 1391 Sandford St., London, ON N5V 4T3 Canada

Full list of author information is available at the end of the article
}

phaseolin constitutes approximately half of total seed protein. Lectins are also abundant, with phytohemagglutinins and $\alpha$-amylase inhibitors accounting for $10 \%$ and $5 \%$ of seed protein, respectively. Like in other grain legumes, the content of essential sulfur amino acids is sub-optimal for nutrition. A strategy proposed to improve protein quality and bioavailability of sulfur amino acids consists in the selection and breeding of highly-digestible phaseolin types [2]. A different approach may rely on variation in storage protein composition.

\section{C) Biomed Central}


Osborn et al. developed genetically related lines integrating mutations conferring a deficiency in phaseolin and major lectins, which are encoded by unique loci [3]. The arcelin-phytohemagglutinin- $\alpha$-amylase inhibitor (APA) locus was introgressed from G12882, a wild accession containing arcelin-1, into the commercial cultivar Sanilac (white navy bean), to generate the SARC1 line. Recessive mutations from Phaseolus coccineus and 'Great Northern 1140' were introgressed into the SARC1 background, conferring a deficiency in phaseolin and lectins, respectively. SMARC1-PN1 lacks phaseolin and SMARC1N-PN1 lacks phaseolin, phytohemagglutinin and arcelin. SARC1, SMARC1-PN1 and SMARC1NPN1 share a similar level (ca. 85\%) of the recurrent parental Sanilac background. Introgression of the APA locus containing arcelin-1 from wild P. vulgaris is associated with resistance to major storage pests, the weevils Zabrotes subfasciatus and Acanthoscelides obtectus [4-6]. However, in the absence of detailed molecular information about the APA locus, the identity of the lectin(s) conferring this resistance remains elusive $[7,8]$.

The deficiency in phaseolin and major lectins, phytohemagglutinin and arcelin, results in a nearly two-fold increase in sulfur amino acid content in seed, particularly of Cys, elevated by $70 \%$, and Met, by 10\% [9]. This takes place mostly at the expense of $S$-methyl-Cys, an abundant non-protein amino acid which cannot substitute for Met or Cys in the diet [10]. Proteomic analysis revealed that the lack of phaseolin and major lectins was mainly compensated by increases in the $11 \mathrm{~S}$ globulin legumin and residual lectins, particularly the $\beta$ subunit of $\alpha$-amylase inhibitor-1, $\alpha$-amylase inhibitor-like protein, mannose lectin FRIL, and leucoagglutinating phytohemagglutinin encoded by PDLEC2 [11]. Several proteins contributing to the increased Cys content including legumin, albumin-2, defensin and albumin-1 were identified on the basis of similarity to related proteins from other legumes. Based on quantification by 2 D gel electrophoresis, legumin levels were raised by $3-$ fold, to $17 \%$ of total protein, while albumin-2 was elevated by 10 -fold, to $1.2 \%$ of total protein. Defensin and albumin-1 could not be quantified accurately as they were characterized from selective extracts.

A significant number of expressed sequence tags (ESTs) have been generated from root, leaf and pod of common bean [12-17], but a similar resource is lacking for the seed, despite its nutritional importance. In addition, transcript profiling studies of common bean using high density arrays have so far relied on cross-specific hybridization to soybean platforms $[18,19]$, in part due to a lack of relevant sequence information. The objective of this study was to generate a common bean EST collection which would provide a foundation to further investigate the metabolism of sulfur amino acids in developing seeds, by using a functional genomic approach. Four seed developmental stages were sampled in the reference genotype BAT93 [20], corresponding to distinct stages of accumulation of $\gamma$-Glu-S-methyl-Cys, the major soluble form of $S$-methyl-Cys. In silico analysis revealed the occurrence of several pathways of sulfur metabolism ranging from sulfate assimilation to (homo) glutathione biosynthesis. Analysis of EST clusters provided detailed information on the identity and abundance of storage protein transcripts. Integration with proteomic data enabled isolation of cDNAs coding for legumin, albumin-2, defensin and albumin-1 isoforms which are elevated in the absence of phaseolin and major lectins. These proteins have a higher Cys than Met content, providing an explanation for the preferential increase of Cys in SMARC1N-PN1.

\section{Results}

\section{Selection of seed developmental stages and generation} of ESTs

Free amino acids were profiled at eight developmental stages of BAT93 seed, to identify stages suitable to generate ESTs (see Additional File 1). Developmental stages are designated after Walbot et al. [21]. According to this nomenclature, storage protein transcripts reach their maximal levels between stages IV (cotyledon) to VI (maturation), while storage products are accumulated between stages V (cotyledon) to VII (maturation) [22]. During stage VIII (maturation) the seed undergoes desiccation. Amino acid content was normalized over the average of developmental stages, expressed in $\log _{2}$ scale, and $k$-means analysis performed to reveal common developmental patterns. Amino acids were grouped into five clusters (Figure 1). The levels of most free amino acids decreased markedly between stages V to VII during which protein reserves are actively accumulated. The nitrogen-rich amino acids, Arg, His and Lys formed a cluster with Phe. Amino acids in this cluster were characterized by a marked rise in their levels during the transition to seed desiccation and dormancy. The second and third clusters contained central intermediates in amino acid metabolism, Ser, Glu, Ala, Gln and Asn, along with Leu and Met. Their levels generally decreased throughout seed development. This decline was more pronounced for amino acids in the third cluster which included Met. $\gamma$-Glu-S-methyl-Cys and $\gamma$-Glu-Leu formed a unique cluster as their levels rose throughout seed development. $\gamma$-Glu-S-methyl-Cys showed a biphasic curve of accumulation, with a continuous rise until stage $\mathrm{V}$, followed by a plateau until stage VII, and a resumption of accumulation from stage VIII (see Additional file 1, Figure 1). In comparison, the levels of free $S$-methyl-Cys were high at stages III and IV, and decreased at stages V and VI, in parallel with Met levels. 


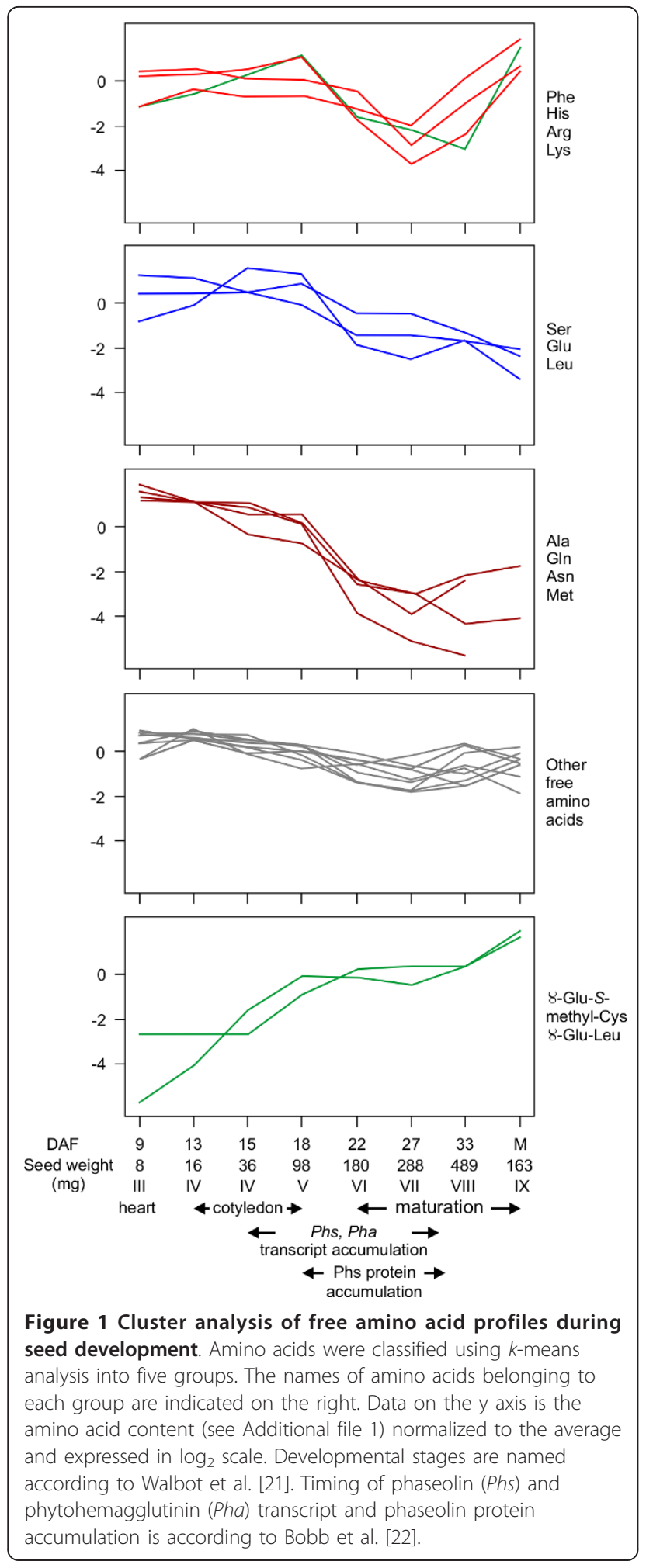

Four developmental stages were selected to generate ESTs, corresponding to distinct phases of $\gamma$-Glu-Smethyl-Cys accumulation: stage IV - cotyledon [14 days after fertilization (DAF), $29 \mathrm{mg}$ seed weight] and stage
$\mathrm{V}$ - cotyledon (16 DAF, $48 \mathrm{mg}$ seed weight), coinciding with early $\gamma$-Glu-S-methyl-Cys accumulation, stage VI maturation (21 DAF, $164 \mathrm{mg}$ seed weight), coinciding with the lag phase, and stage VIII - maturation (30 DAF, $380 \mathrm{mg}$ seed weight), coinciding with the resumption of accumulation. A total of 8,725, 9,537, 5,260 and 6,625 ESTs were generated for each respective developmental stage. Of these, Gene Ontology (GO) annotation from Arabidopsis [23] was retrieved for 5,511, 3,825, 1,561 and 3,303 ESTs, respectively. Assembly of the total 30,147 ESTs yielded 3,658 contigs and 6,027 singletons.

\section{In silico analysis of ESTs identifies features of sulfur and amino acid metabolism in developing seeds}

The representation of general GO categories of biological process and molecular function was analyzed during seed development. The percentage of ESTs assigned to a GO category (see Additional file 2) was normalized to the average over seed development, expressed in $\log _{2}$ scale and submitted to hierarchical clustering analysis (Figure 2). Categories of cellular metabolism, primary metabolism, macromolecule metabolism and cellular protein metabolism clustered together. Their representation suggested that general metabolic activity was highest at stage IV, progressively decreased until stage VI and then increased at stage VIII. The same general trend was observed for the categories of amino acid and sulfur compound metabolic processes. The decline in metabolic activity coincided with accumulation of storage products. Indeed, the nutrient reservoir activity category was most highly represented at stage VI, followed by stage V. The latter clustered away from all other categories. Hormone biosynthesic process also had a unique profile, being highest at the first stage of development and markedly down at the last two stages. The percentage of ESTs assigned to the category of photosynthesis was highest at stage IV, followed by stage V, and further decreased at stages VI and VIII, consistent with the loss of chlorophyll pigmentation in cotyledons during seed maturation [21]. Interestingly, categories of photosynthesis, response to oxidative stress and response to radiation were grouped together. The category of response to water deprivation had highest levels at stage VIII, corresponding to seed desiccation. Analysis of GO categories related to the supply of nitrogen to developing seeds indicated that ureide catabolism, comprising allantoinase and allantoicase activities, was most highly represented at stage V, coinciding with the onset of storage protein accumulation, whereas the percentage of ESTs associated with asparaginase activity increased steadily until stage VI, the midpoint of storage protein accumulation (Figure 3A).

Five different GO categories were associated with Arg metabolism (Figure 3B). Of these, argininosuccinate 

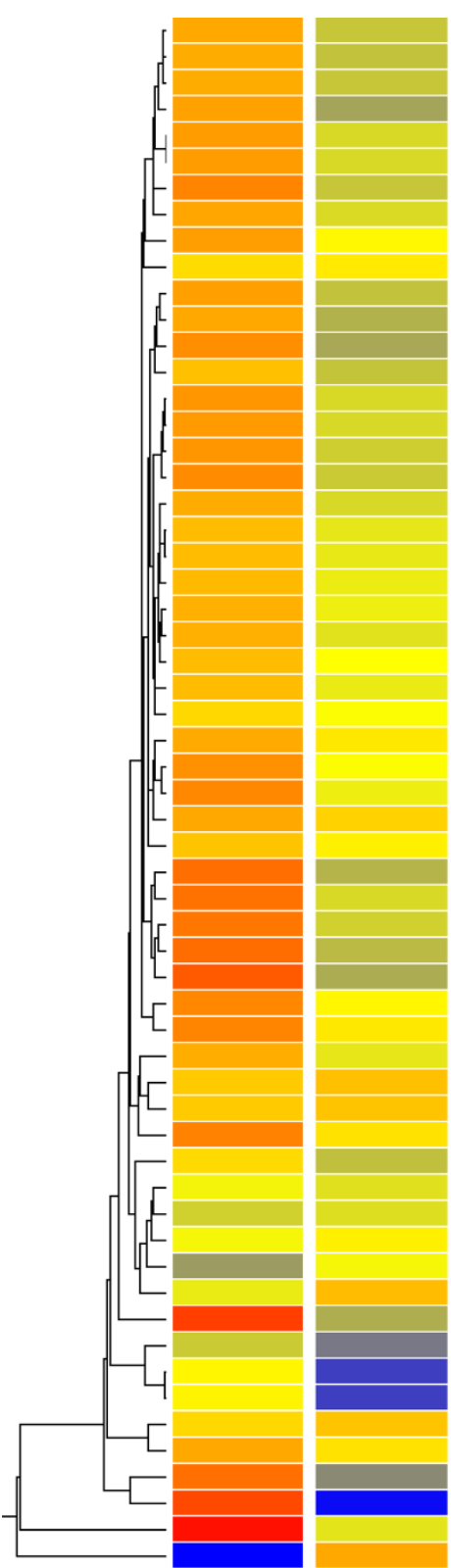

IV

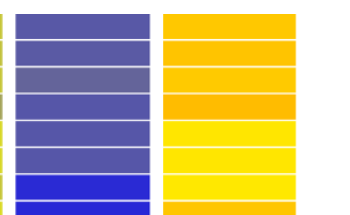

$+$
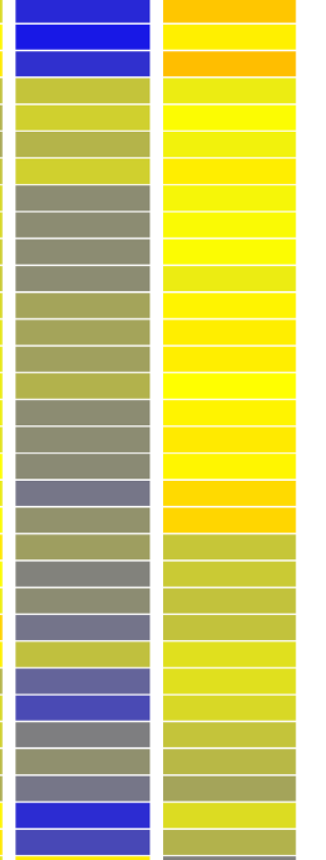

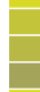

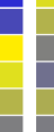

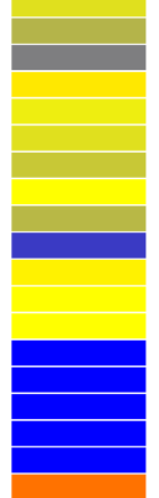

VI

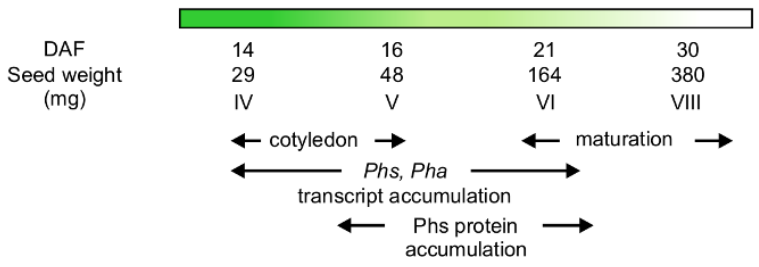

embryonic development ending in seed dormancy 0009793

seed development 0048316

embryonic development 0009790

transcription regulator activity 0030528

macromolecule localization 0033036

establishment of protein localization 0045184

response to osmotic stress 0006970

regulation of metabolic process 0019222

multicellular organismal developmental process 0044236

sulfur compound metabolic process 0006790

hormone-mediated signaling 0009755

response to cold 0009409

response to stress 0006950

response to abiotic stimulus 0009628

cellular metabolic process 0044237

primary metabolic process 0044238

macromolecule metabolic process 00443170

cellular protein metabolic process 0044267

catabolic process 0009056

establishment of localization 0051234

transport 0006810

transporter activity 0005215

establishment of cellular localization 0051649

binding 0005488

translation regulator activity 0045182

generation of precursor metabolites and energy 0006091

catalytic activity 0003824

response to jasmonic acid stimulus 0009753

nitrogen compound metabolic process 0006807

amino acid metabolic process 0006250

antioxidant activity 0016209

secretion 0046903

response to hormone stimulus 0009725

post-embryonic development 0009791

biosynthetic process 0009058

amino acid biosynthetic process 0008652

structural molecule activity 0005198

metabolic process 0008152

secondary metabolic process 0019748

gibberellic acid mediated signaling 0009740

response to radiation 0009314

response to oxidative stress 0006979

photosynthesis 0015979

response to abscisic acid stimulus 0009737

response to temperature stimulus 0009266

enzyme regulator activity 0030234

system development 0048731

response to heat 0009408

response to wounding 0009611

response to gibberellin stimulus 0009739

response to salicylic acid stimulus 0009751

response to water 0009415

response to water deprivation 0009414

response to hypoxia 0001666

molecular transducer activity 0060089

response to auxin stimulus 0009733

auxin mediated signaling pathway 0009734

hormone biosynthetic process 0042446

nutrient reservoir activity 0045735

Figure 2 Cluster analysis of general GO category profiles during seed development. GO categories were classified by hierarchical clustering analysis. The percentage of ESTs assigned to a GO category (see Additional file 2) was normalized to the average and expressed in a log 25 scale. GO category name and number is shown on the right. The horizontal bar represents seed color related to photosynthetic capacity [21]. 
A)

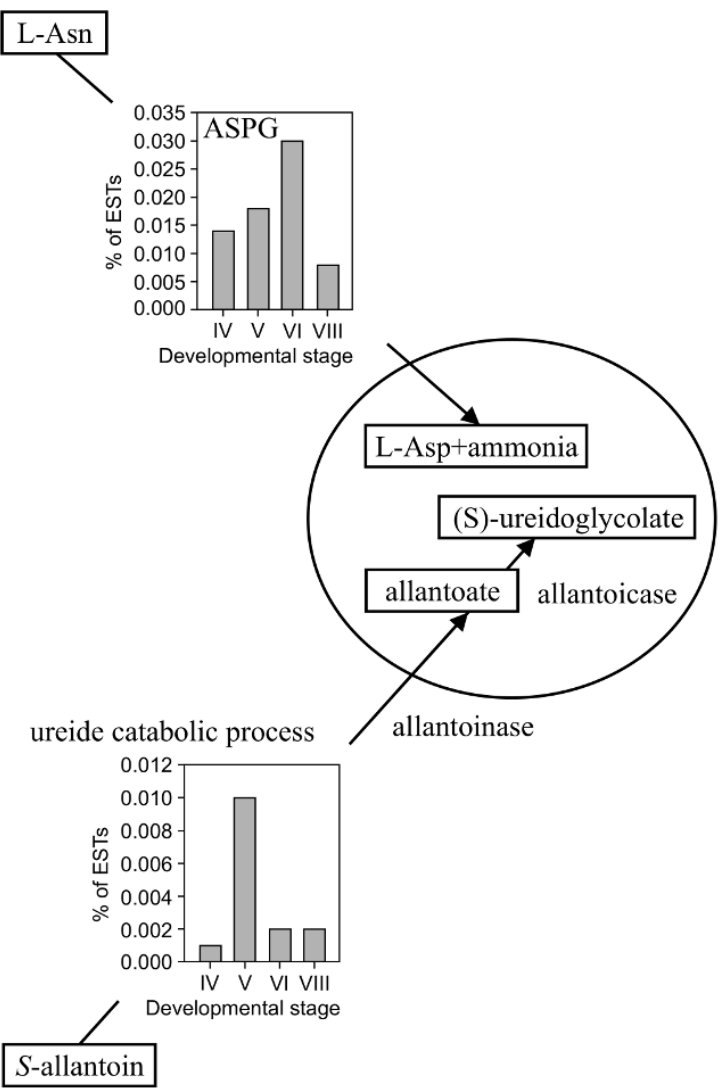

B)

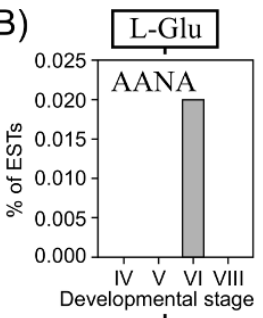

$+$

$N$-acetyl-L-Glu

$N$-acetyl-L-Glu-

5 -semialdelyde

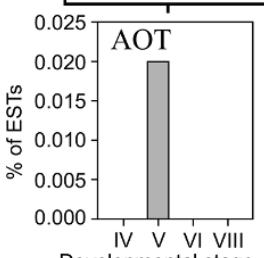

Developmental stage

$+$
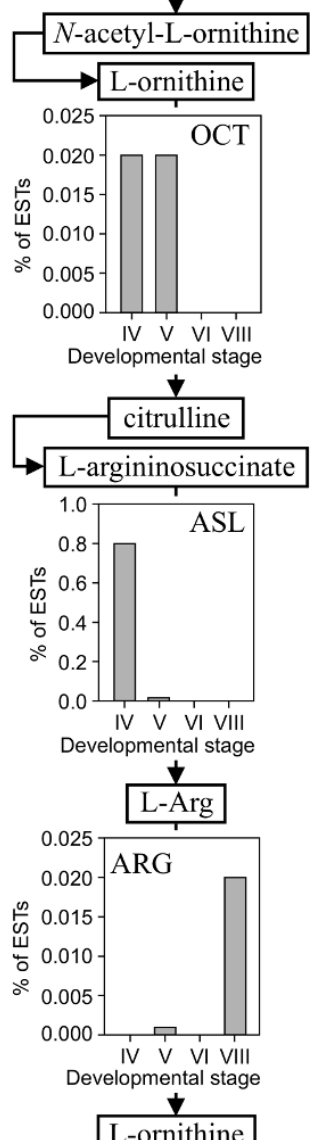

Figure 3 Representation of GO categories related to nitrogen supply (A) and Arg metabolic pathway (B) during seed development Percentage of ESTs is displayed for each developmental stage. Abbreviations and GO category numbers are as follows: ASPG: asparaginase activity - 0004067; ureide catabolic process - 0010136 (allantoinase and allantoicase); AANA: amino acid N-acetyltransferase activity - 0004042 (Nacetyl Glu synthase); AOT: acetylornithine transaminase activity - 0003992; OCT: carboxyl or carbamoyltransferase activity - 0016743 (ornithine carbamoyltransferase); ASL: argininosuccinate lyase activity - 0004056; ARG: arginase activity - 0004053. 
lyase activity, the last step in Arg biosynthesis, was represented by a high percentage of ESTs at stage IV, of $0.80 \%$. This correlates with an increase in steady-stage Arg levels between stages III to V (see Additional File 1). Analysis of categories related to sulfur metabolism indicated that all enzymatic activities associated with sulfur assimilation, de novo Cys and Met biosynthesis were represented in the EST dataset (Figure 4). These include sulfate adenylyltransferase, adenylyl-sulfate reductase and sulfite reductase; Ser $O$-acetyltransferase and Cys synthase; and cystathionine $\gamma$-synthase, cystathionine $\beta$-lyase and Met synthase. Homocysteine $S$-methyltransferase, involved in the production of Met via the $S$-methylmethionine cycle, the catabolic enzyme Met $\gamma$-lyase and the two enzymes involved in (homo) glutathione biosynthesis, Glu-Cys ligase and (homo)glutathione synthase, were also represented.

\section{Analysis of seed protein ESTs}

Clustering of ESTs is an efficient tool to estimate the identity and abundance of transcripts in a complex mRNA sample. This analysis focused on the sulfur-poor $7 \mathrm{~S}$ globulin phaseolin and lectins, the most abundant seed proteins in commercial cultivars [1], and on the sulfur-rich $11 \mathrm{~S}$ globulins, $2 \mathrm{~S}$ albumins, and defensins whose levels are elevated in the absence of phaseolin and phytohemagglutinin [11]. To identify contigs coding for sulfur-rich proteins induced in mature seed of SMARC1N-PN1, conceptual translations of sequences were compared with de novo sequenced peptides from previously obtained liquid chromatography-tandem mass spectrometry (LC-MS/MS) data [11]. Corresponding cDNAs were isolated.

\section{Sulfur-poor 7S globulin phaseolin and lectins}

Within this subset, most ESTs were derived from the genes encoding the $\alpha$ - and $\beta$-subunit of S-type phaseolin, which differ by the presence of a 27 base pair insertion, and are present in cultivated varieties representative of the Mesoamerican gene pool $[24,25]$ (Figure 5). The lectin encoded by lec4-B17 and phytohemagglutinin encoded by pha- $E[26]$ were the next most highly represented, followed by $\alpha$-amylase inhibitor-1 [27] and $\alpha$ amylase inhibitor-like protein [28]. Fewer ESTs were observed for the leucoagglutinating phytohemagglutinin encoded by PDLEC2 [29], and an additional phytohemagglutinin previously isolated from an arcelin-5 genotype [30]. The phytohemagglutinin encoded by pha-L [26] and mannose lectin FRIL [31], previously identified in SARC1 and SMARC1N-PN1 [11], were not represented in the BAT93 EST dataset. Conversely, the arcelin-5 phytohemagglutinin was not previously identified in SARC1 or SMARC1N-PN1 [11]. There was no evidence for additional phaseolin or lectin transcripts in BAT93. The phytohemagglutinins identified here are encoded by distinct genes, as they share only between 80 to $87 \%$ identity in their deduced amino acid sequence.

\section{Sulfur-rich 115 globulins, 25 albumins and defensins}

Among sulfur-rich proteins, clustering of ESTs yielded three legumin, three albumin-2, four defensin and eleven albumin-1 contigs or singletons. Within each protein type, the isoform induced in SMARC1N-PN1 was encoded by the most highly represented contig in the BAT93 EST collection (Figure 5).

The major legumin cDNA encodes a protein of 606 amino acids (Figure 6). Removal of the signal peptide, spanning residues 1 to 23, generates a precursor with a predicted molecular weight of $66.3 \mathrm{kD}$. Cleavage after the conserved $\mathrm{Asn}^{427}$ residue gives rise to an acidic $\alpha$ subunit, with a predicted molecular weight of $46.4 \mathrm{kD}$ and $\mathrm{pI}$ of 5.45 , and a $\beta$-subunit, with a predicted molecular weight of $19.8 \mathrm{kD}$ and $\mathrm{pI}$ of 7.03 . The $\alpha$-subunit contains a Glu-rich domain, spanning positions 260 to 415. Conventional $\mathrm{N}$-terminal and de novo peptide sequencing support the location of the cleavage sites $[11,32]$. De novo sequenced tryptic peptides from replicate samples of 2-D gel spots [11] covered 48 and $79 \%$ of the deduced sequences of the $\alpha$ - and $\beta$-subunits, respectively (Figure 6 and see Additional file 3A). The $P$. vulgaris legumin amino acid sequence shares 54 and 41\% identity with glycinin A5A4B3 from Glycine max and arachin 5 from Arachis hypogaea [33], respectively, but is more similar in length to arachin 5. Phylogenetic analysis indicated that the $P$. vulgaris protein belongs to a group of $11 \mathrm{~S}$ globulins from legumes, comprising Btype, Met-poor legumins from Vicia species [34] (Figure 7 ). The $P$. vulgaris legumin is part of a subgroup of high molecular weight legumins which includes group-2 glycinins from soybean [35], arachin 5, legumin storage proteins 2 and -3 from Lotus japonicus [36], the minor small legumin from Pisum sativum [37] and leguminrelated high molecular weight polypeptide from Vicia faba [38]. Members of this subgroup are characterized by an extended $\mathrm{C}$-terminal half of the $\alpha$-subunit arising by expansion and mutation of a sequence repeat.

The albumin- 2 cDNA encodes a protein of 277 amino acids with $80 \%$ identity to a seed albumin from Vigna radiata and $49 \%$ identity to albumin- 2 from $P$. sativum [39] (Figure 8A). The protein contains four hemopexinlike repeats implicated in polyamine binding [40]. De novo sequenced tryptic peptides from replicate samples of 2-D gel spots covered $74 \%$ of the deduced sequence of the mature polypeptide (Figure $8 \mathrm{~A}$ and see Additional file 3B) [11]. The de novo sequencing data indicated that the $\mathrm{N}$-terminal Met residue is absent in the mature polypeptide.

The defensin highly expressed in SMARC1N-PN1 had been previously identified on the basis of its similarity to a defensin from Cicer arietinum [11]. However, 


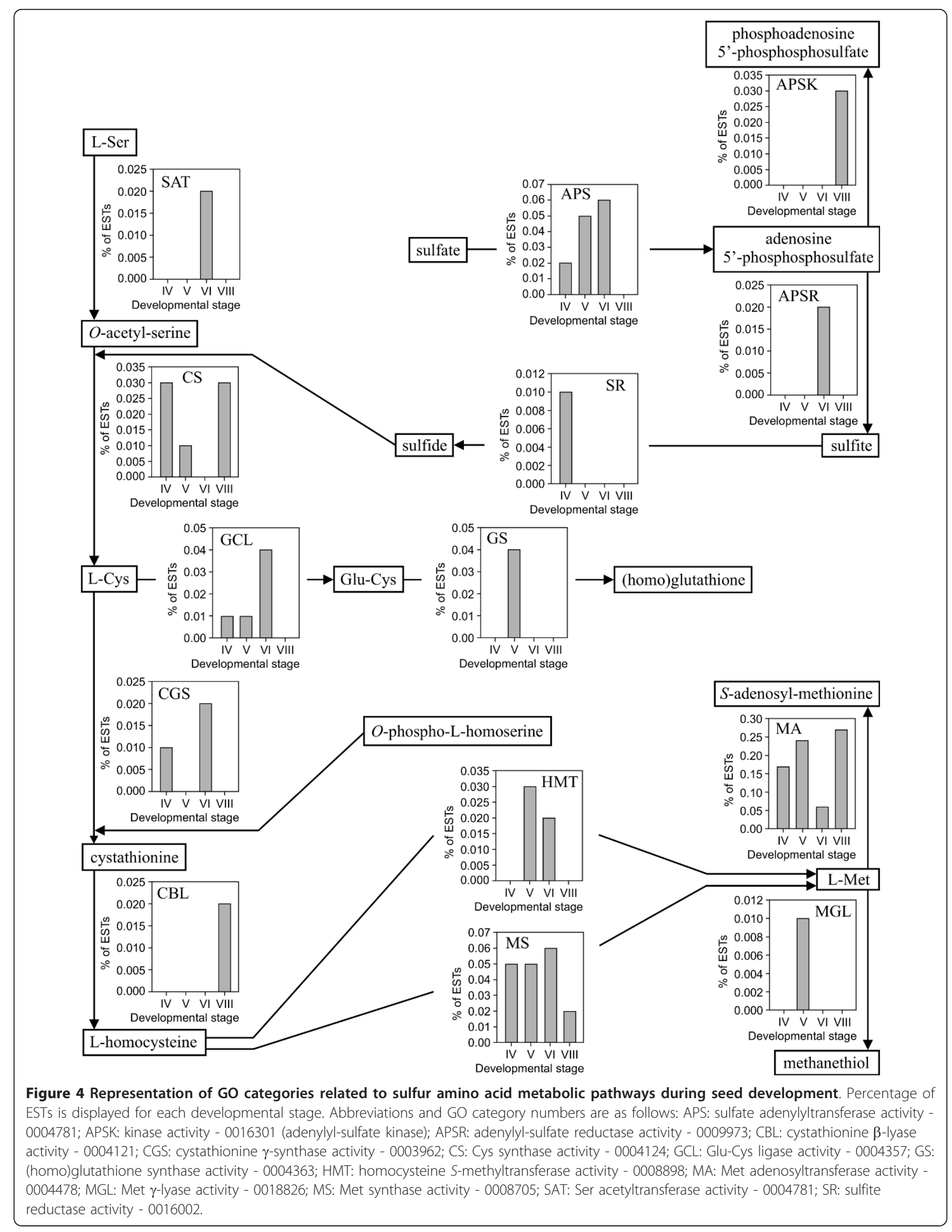




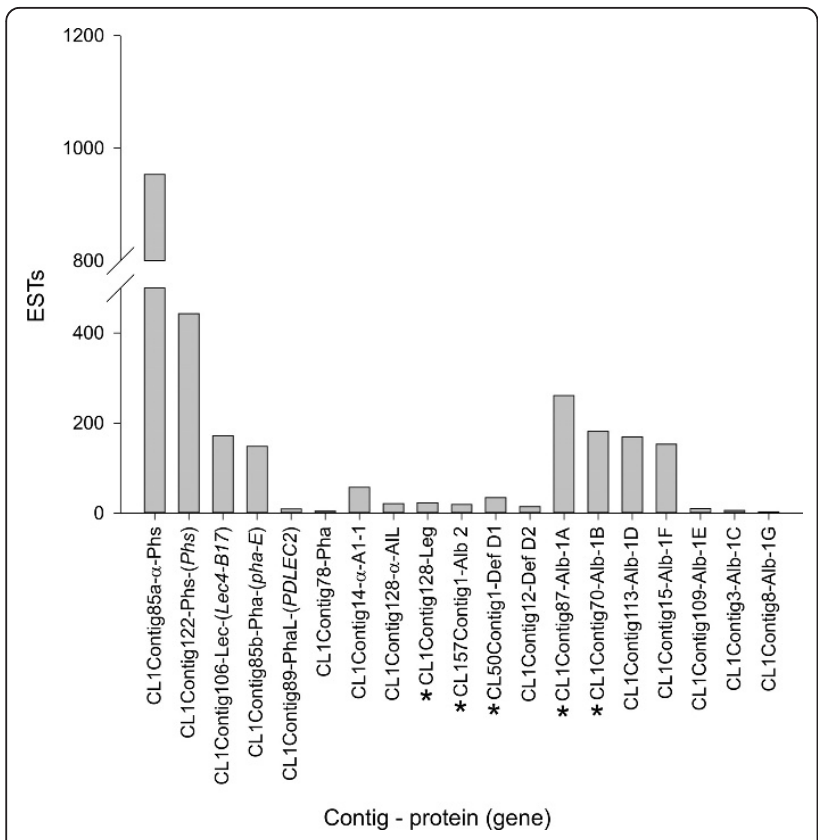

Figure 5 Transcript expression of seed proteins in the BAT93 line. Phaseolin and lectin contigs were annotated on the basis of nearest BLASTx hit in the UniProt database, with e-value ranging between 0 to $1.00 \mathrm{E}-115$. For sulfur-rich proteins, only full-length contigs are represented. Contigs coding for sulfur-rich proteins elevated in SMARC1N-PN1, lacking phaseolin, phytohemagglutinin and arcelin, are marked with an asterisk. Phs, phaseolin; Lec, lectin; Pha, phytohemagglutinin; PhaL, leucoagglutinating

phytohemagglutinin; Al, amylase inhibitor; AlL, amylase inhibitor-like protein.

associated tryptic peptide sequences actually belong to antifungal defensin D1 from P. vulgaris [41], whose partial cDNA and N-terminal amino acid sequences were absent from databases. The defensin D1 cDNA isolated here encodes a precursor of 75 residues with 93\% identity to defensin D2 from $V$. radiata [42]. The mature peptide is characterized by a Cys-stabilized $\alpha \beta$ motif, consisting of three $\beta$-strands and one $\alpha$-helix held by four disulfide bridges. The two tryptic peptides previously identified [11], spanning positions 30 to 39 and 40 to 53 , are the only ones within range of detection by the mass spectrometer. The second most abundant contig, and associated defensin D2 cDNA, encode a precursor polypeptide with $93 \%$ identity to a defensin from Vigna unguiculata. Defensins D1 and -2 are 37\% identical in amino acid sequence.

Two albumin-1 cDNAs, albumin-1A and - B may encode the methanol-soluble albumin-1 highly expressed in SMARC1N-PN1. Their deduced amino acid sequences are $97 \%$ identical. They encode polypeptide precursors of 127 amino acids with $88 \%$ identity to a partial albumin-1 from P. vulgaris [43], and 71\% identity to albumin-1 from G. $\max$ [44] (Figure $8 \mathrm{~B}$ ). The precursors give rise to chains b (residues 28 to 64) and a (residues 73 to 124) [45]. The b chain is arranged in a knottin-fold containing three $\beta$-strands held by three disulfide bridges $[46,47]$. The peptide previously de novo sequenced spans residues 49 to 63 of the b chain [11]. The presence of an Arg at position 63 generates a tryptic site unique to albumin-1A and $-\mathrm{B}$, among the albumin-1 isoforms represented in the EST dataset.

Availability of cloned cDNAs provides information about the sulfur amino acid content of sulfur-rich proteins whose levels are elevated in SMARC1N-PN1. The mature legumin subunits contain $0.9 \%$ of their residues as Cys and $0.7 \%$ as Met. Mature albumin-2 contains $1.3 \%$ of Cys and $0.4 \%$ of Met. Mature defensin D1 is particularly rich in Cys at $17 \%$ and lacks Met residues. The mature albumin-1A and $-\mathrm{B}$ subunits have a Cys content of $11 \%$, and a Met content of 3.3 and $2.2 \%$, respectively.

\section{Purification of legumin}

To further characterize legumin, this protein was purified from SMARC1N-PN1 by targeting the most abundant 2$\mathrm{D}$ gel spots, 78 to 80 (59-64 kD and pI value of 5.5-5.6), corresponding to its $\alpha$-subunit and representing $10 \%$ of total protein [11]. The apparent pI value was used to select conditions for purification by ion exchange chromatography. Fractions were screened by SDS-PAGE for bands having the appropriate molecular weight. Ammonium sulfate precipitation followed by ion exchange chromatography yielded two fractions of interest, characterized by size exclusion chromatography. Proteins were identified after in-gel trypsin digestion and LC-MS. The first fraction contained group 3 late embryogenesis abundant protein with an apparent molecular weight of 56.0 kD (Figure 9A; see Additional file 3C). In 2-D gels, this protein migrated to spots $84(64 \mathrm{kD}$ and $\mathrm{pI}$ value of 5.4) and 104 (55 kD and $\mathrm{pI}$ value 5.4-5.5), having apparent molecular weight and pI values close to those of the legumin $\alpha$-subunit. The native molecular weight of group 3 late embryogenesis abundant protein was measured as $494 \pm 2 \mathrm{kD}$ (average \pm standard deviation; $n=3$ ), suggesting a multimer of nine identical subunits. The second fraction contained the legumin polypeptide precursor, $\alpha$ and $\beta$-subunits, with apparent molecular weights of 73.4, 54.8 and 21.9 kD respectively (Figure 9C; see Additional file 3D-F). Two minor bands, of 44.0 and $42.7 \mathrm{kD}$ were also identified as the $\alpha$-subunit (see Additional file 3G). Detection of the mass of a tryptic peptide, 423NRGSNGIEETLCTLK-437, containing an intact cleavage site was characteristic of the precursor. A complex pattern of elution was observed after size exclusion chromatography (Figure 9B and 9C). A first peak contained all three major polypeptides, with a molecular weight of 704 $\pm 36 \mathrm{kD}$, suggesting possible associations between trimers 


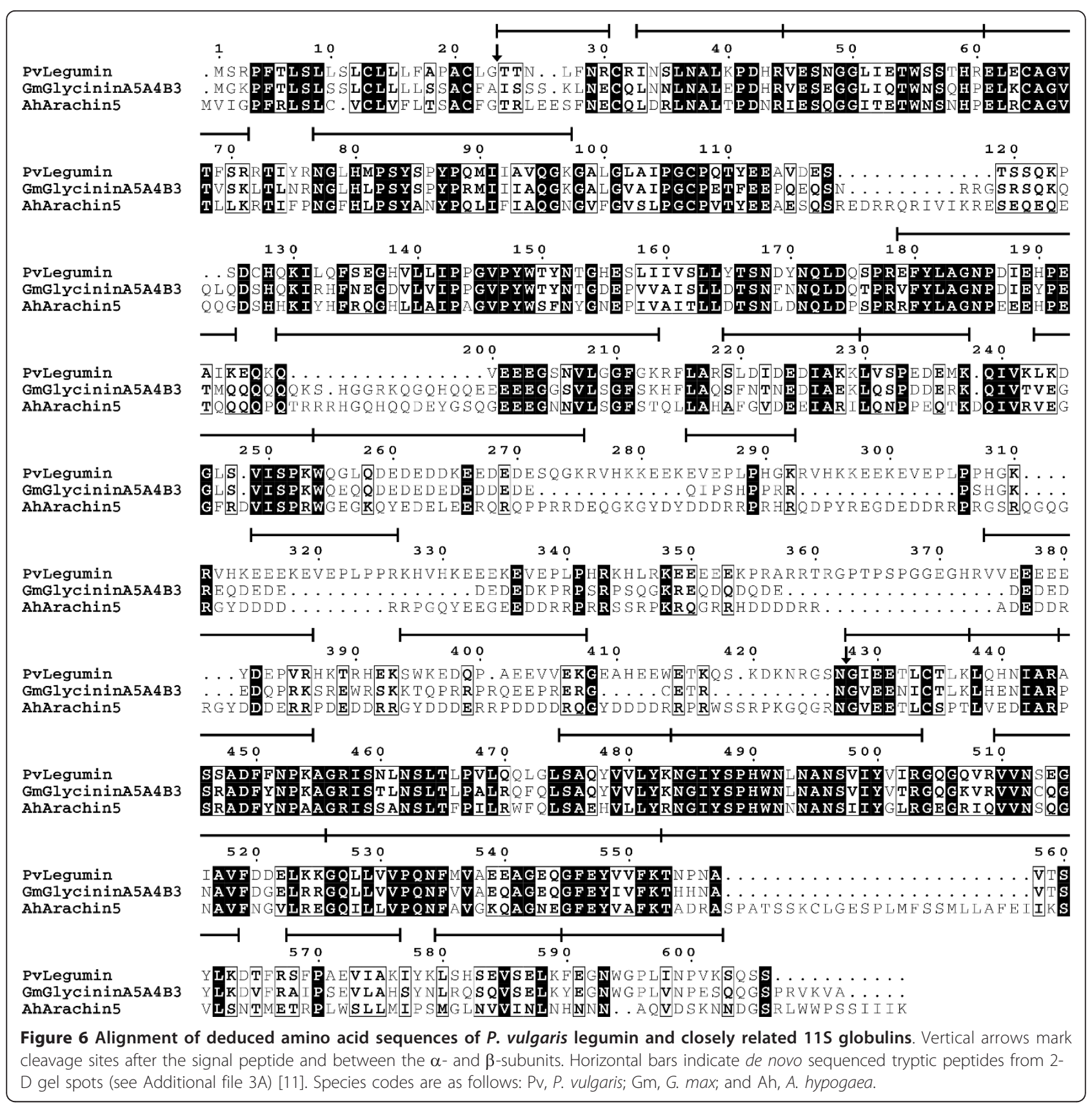

of the precursor and hexamers of $\alpha$ - and $\beta$-subunit. A second peak contained the $\alpha$-subunit alone, with a molecular weight of $282 \pm 2 \mathrm{kD}$, suggesting a hexamer. Recovery of the $\alpha$-subunit alone may be related to the inclusion of reducing agent during purification.

\section{Discussion}

Profiling of free amino acids in BAT93 seeds enabled a rational selection of developmental stages to generate ESTs, which correspond to distinct phases of $\gamma$-Glu-Smethyl-Cys accumulation. Analysis of general GO categories related to primary metabolism, photosynthesis, response to water deficit and nutrient reservoir activity validated the representativeness of ESTs at the different stages. Free amino acid and GO category profiles confirm and extend the findings of Fait et al. [48] on the metabolic transitions to storage product accumulation and desiccation in Arabidopsis seeds. They highlighted a decrease in the levels of free amino acids, particularly Asn, Gln and Lys, during reserve accumulation, indicative of metabolic transformations and efficient incorporation into storage proteins. Nitrogen-rich 


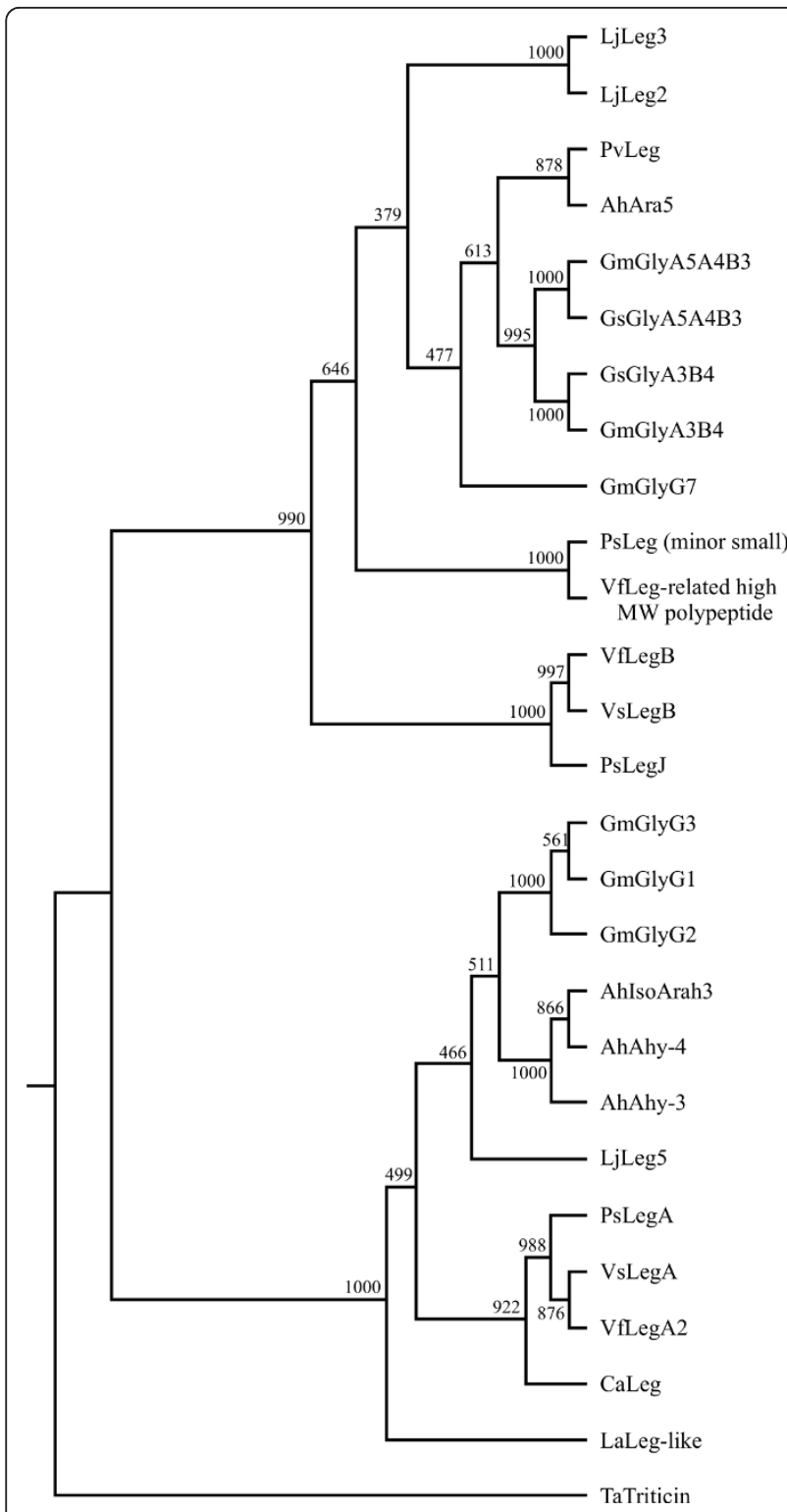

Figure 7 Phylogenetic tree of $11 \mathrm{~S}$ globulins. Numbers at the fork of the unrooted tree indicate the number of times the group of sequences to the right of that fork occurred among a data set of 1,000 trees. Abbreviations are as follows: Leg, legumin; Ara, arachin; and Gly, glycinin. Species codes are as in Figure 6 and also include: Lj, L. japonicus; La, Lupinus albus; Gs, Glycine soja; Vf, V. faba; Vs, Vicia sativa; Ps, P. sativum; Ca, C. arietinum; and Ta, Triticum arvense.

amino acids, Asn, Lys and Arg, were transiently elevated during the transition to seed desiccation, suggesting their role as a nitrogen source to support germination prior to the mobilization of storage protein. The same was true of aromatic amino acids, Trp, Phe and Tyr, which may support the biosynthesis of shikimate-derived compounds for defense and indole-acetic acid during germination. Steady-state transcript levels of most enzymes of primary metabolism examined had reduced levels during the active phase of reserve accumulation.

The biphasic accumulation of $\gamma$-Glu-S-methyl-Cys is consistent with a function of $S$-methyl-Cys as a storage form of excess sulfur. During the lag phase, incorporation of sulfur amino acids into storage proteins may efficiently compete with the biosynthesis of $S$-methyl-Cys. Based on the high levels of free $S$-methyl-Cys detected at stages III and IV, substantial flux through this metabolite may lead to accumulation in the $\gamma$-glutamyl dipeptide form. The rise in Arg levels between stages III to $\mathrm{V}$ suggests a transient accumulation of nitrogen into this nitrogen-rich amino acid in anticipation of active storage protein accumulation. This increase may be mediated by arginosuccinate lyase activity, whose transcript is overrepresented during stage IV.

Analysis of GO categories related to sulfur metabolism revealed the occurrence of complete pathways of sulfate assimilation, de novo Cys and Met biosynthesis. Similar findings have been reported for soybean seed [49]. These data may be interpreted in relation with current understanding of the sulfur nutrition of legume seed. The main sources of sulfur transported to the seed are expected to be $S$-methylmethionine [50] and homoglutathione [51]. In soybean, most sulfate appears to be converted to homoglutathione in the pod, prior to uptake by developing cotyledons, although some is detected in developing seed [52]. However, under sulfur-limiting conditions, glutathione exclusively, and no sulfate, is translocated to the seed, according to a model developed in wheat [51]. Interestingly, Arabidopsis knock-out mutants of sulfate transporters that have been characterized so far show increased sulfate content in mature seed, suggesting a function in intracellular transport rather than uptake by the embryo [53,54]. Beside the generation of sulfide for de novo Cys biosynthesis, the sulfate assimilatory pathway is required for the biosynthesis of the activated nucleotide 3'-phospho-5'-adenosinephosphosulfate, the universal donor in sulfate transfer reactions. Adenylyl-sulfate kinase activity, forming 3'-phospho-5'-adenosinephosphosulfate, which competes with adenylyl-sulfate reductase for its substrate, was represented in the EST dataset (Figure 4). Cystathionine $\gamma$-synthase and - $\beta$-lyase likely provide homocysteine as an acceptor for methyl transfer from $S$-methylmethionine, catalyzed by homocysteine $S$ methyltransferase [55], while Met synthase is essential to recycle homocysteine produced in the $S$-adenosylmethionine cycle, which appeared highly active according to the high representation of the Met adenosyltransferase activity category. Further research is required to fully understand the significance of the sulfate assimilatory pathway, and the relative contributions of de novo Cys and Met biosynthesis in seed metabolism. 

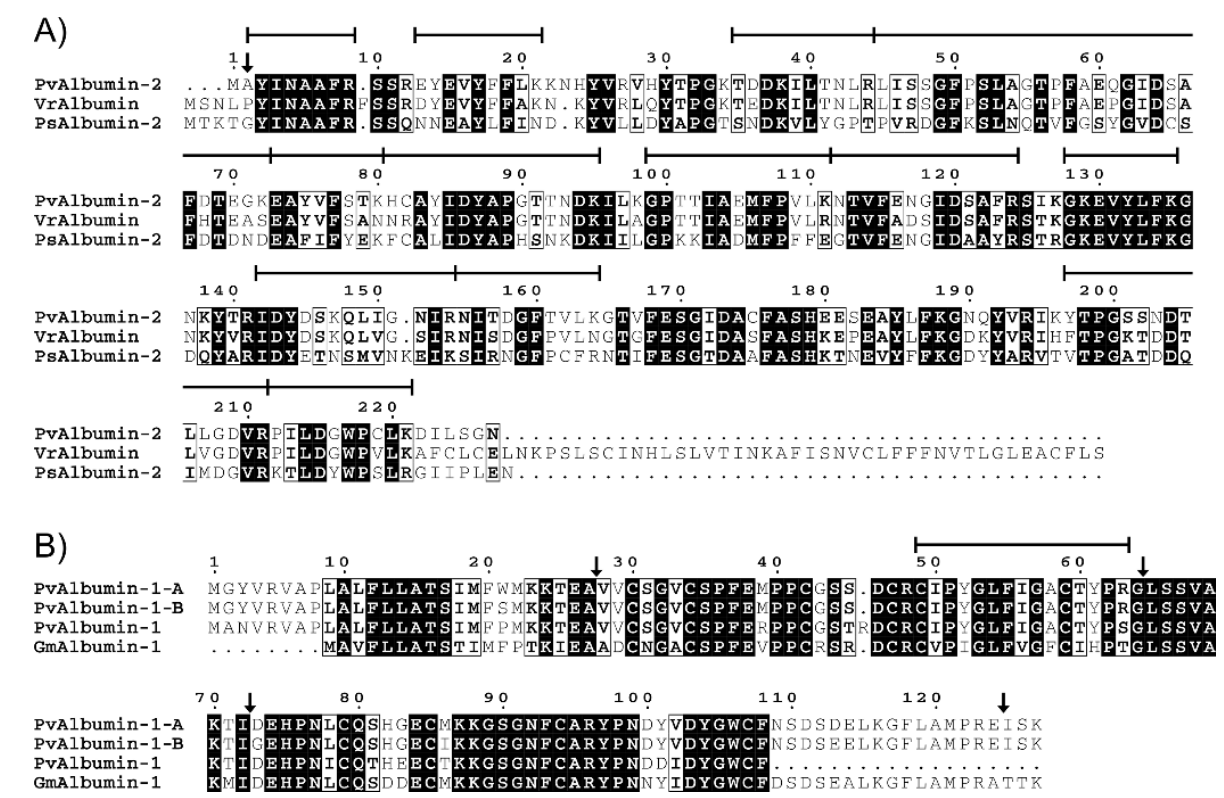

Figure 8 Alignment of deduced amino acid sequences of $P$. vulgaris albumin-2 (A) and albumin-1 (B) with related proteins. Vertical arrows mark cleavage sites of polypeptide precursors. Horizontal bars indicate de novo sequenced tryptic peptides from 2-D gel spots and SDSPAGE bands from methanol soluble extracts (see Additional file 3B) [11]. Species codes are as in Figures 6 and 7 and also includes: Vr, V. radiata.

Previous results have shown that the absence of Cyspoor phaseolin and phytohemagglutinin in SMARC1NPN1 leads to a shift of sulfur from $S$-methyl-Cys to the protein Cys pool [9]. By integrating proteomic and EST data, the deduced sequences of several proteins contributing to the increased levels of sulfur amino acids in SMARC1N-PN1 were identified. These proteins have a higher Cys than Met content, providing an explanation for the preferential increase in Cys over Met in the mutant line.

Legumin is found at relatively low levels of ca. $3 \%$ of seed protein in common bean cultivars, as compared with other grain legumes [32]. Identification of its deduced amino acid sequence establishes that it is a member of the high molecular weight $11 \mathrm{~S}$ globulins. The mechanism leading to the evolution of high molecular weight $11 \mathrm{~S}$ globulins involves expansion of a repeat sequence at the $\mathrm{C}$-terminal end of the $\alpha$-subunit. The sequences of these repeats differ between $P$. vulgaris legumin, arachin 5 and glycinin A5A4B3 (Figure 6). Legumin has four instances of the sequence $\mathrm{NH}_{2}$ HKEEEKEVEPLP-COOH, compared with four of the sequence $\mathrm{NH}_{2}$-GYDDD[E/D]RRP-COOH and eight of the sequence $\mathrm{NH}_{2}-\mathrm{DDD}[\mathrm{E} / \mathrm{D}] \mathrm{RR}-\mathrm{COOH}$ in arachin 5 . Glycinin A5A4B3 has three repeats of the sequence $\mathrm{NH}_{2}$-QDEDEDEDED-COOH, compared with two in
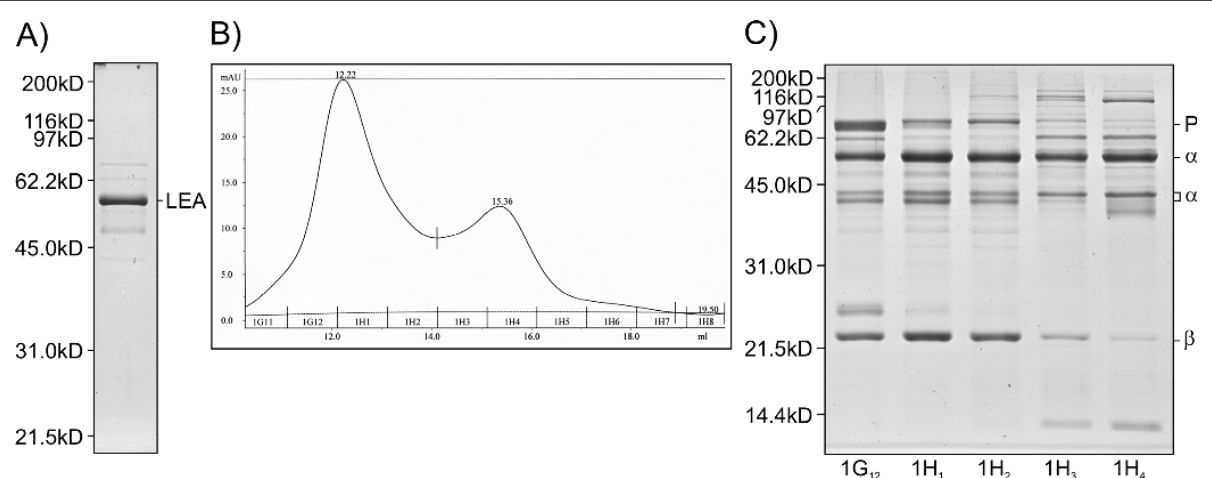

Figure 9 Purification of abundant proteins of $\mathbf{5 6}$ kD from SMARC1N-PN1 seeds. SDS-PAGE of purified group 3 late embryogenesis abundant protein (A), and legumin fractions (C) with their elution profile (B). LEA: group 3 late embryogenesis abundant protein; $\mathrm{P}, \alpha$, and $\beta$ refer to prolegumin and its subunits. 
glycinin A4B3 [56]. The first instance of this sequence, spanning positions 258 to 268 of legumin, is relatively well conserved but not repeated in legumin and arachin 5. These observations suggest that expansion of repeats probably occurred, at least in part, after the separation of the lineages leading to the three species.

Purification of legumin revealed substantial accumulation of the propolypeptide in SMARC1N-PN1. A similar finding has been reported in transgenic soybean where the expression of the $\alpha$-and $\alpha^{\prime}$-subunits of the 7S globulin $\alpha$-conglycinin was suppressed [57]. Interestingly, the proglycinin was shown to be trafficked directly from the ER to the vacuole, whereas mature $11 \mathrm{~S}$ globulins transit in the Golgi apparatus. In most legume crops, $\alpha$-subunits of $11 \mathrm{~S}$ globulins have an apparent molecular weight of approximately $40 \mathrm{kD}$. By contrast, $P$. vulgaris and $V$. unguiculata [58] share a single, dominant high molecular weight legumin whose $\alpha$-subunit has an apparent molecular weight of approximately $60 \mathrm{kD}$. Similarly, in L. japonicus, two of three major legumins, the legumin storage proteins 2 and -3 , which are closely related to the $P$. vulgaris legumin, have $\alpha$-subunit apparent molecular weights of 55 and $60 \mathrm{kD}$, respectively [36]. In G. $\max$, an additional cleavage site in proglycinin gives rise to A5 and A4 subunits, having a reduced molecular weight [56]. The significance of the $10 \mathrm{kD}$ difference between the predicted and apparent molecular weight of the major legumin $\alpha$-subunit, and the detection of minor $\alpha$-subunit polypeptides of 44.0 and $42.6 \mathrm{kD}$ is unclear. The minor polypeptides may represent partial degradation products, and the discrepancy in molecular weight may be due to an effect of the Glu-rich domain on electrophoretic behavior. Alternatively, these differences may arise by a possible post-translational modification of the mature $\alpha$-subunit. The absence of this modification in prolegumin, whose predicted and apparent molecular weight is similar, would reflect differences in trafficking, as already noted in soybean. Among high molecular weight legumins in other legume crops, the $\alpha$-subunit of $P$. sativum minor small legumin accumulates only as degradation products ranging from 21 to $32 \mathrm{kD}$, which was interpreted as an outcome of early mobilization [59], while only the $\beta$-subunit of arachin 5 was identified in the mature seed proteome of A. hypogaea [60].

Although phaseolin and lectins have been characterized in great detail, the number and identity of genes encoding these proteins is still unknown. In the present study, there was evidence for only two phaseolin genes in the BAT93 EST dataset. Beside the APA locus on linkage group B4, two lectin loci have been mapped on linkage group B7 [61,62]. EST, proteomic [11], cDNA [26] and genomic sequence data [62] can be integrated to provide information on the composition of the APA locus in different $P$. vulgaris genotypes. In BAT93 and $A R C 5$ genotypes, a gene order consisting in lec4-B17/ $p h a-E /$ phytohemagglutinin/ $\alpha$-amylase inhibitor-like protein can be inferred. In $A R C 1$, arc3 and arc4 genotypes, the arcelin-5 phytohemagglutinin appears to be substituted with pha-L. PDLEC2 encoding leucoagglutinating phytohemagglutinin, isolated from a phytohemagglutinin-deficient Pinto cultivar [29], whose expression is elevated in SMARC1N-PN1, may be one of the lectin genes located outside of the APA locus.

\section{Conclusions}

The BAT93 EST collection provides a foundation to initiate further studies of sulfur amino acid metabolism in developing seed, as all relevant pathways and enzyme activities are represented. The results presented here are consistent with a mechanism whereby sulfur can be efficiently partitioned between $S$-methyl-Cys and Cys, but its metabolic basis is not understood. The identification and characterization of sulfur-rich proteins whose levels are increased in the absence of phaseolin and major lectins provides an explanation for the preferential increase in Cys over Met.

\section{Methods}

\section{Plant material and growth conditions}

BAT93, a line representative of the Mesoamerican gene pool of common bean (Phaseolus vulgaris) [20], was grown as previously described [63]. Developing seed samples were harvested randomly from about twenty plants. SMARC1N-PN1 [3] was grown in the field in London, ON, in 2008.

\section{Extraction and quantification of free amino acids}

Amino acids were extracted and quantified by HPLC after derivatization with phenylisothiocyanate as previously described [9], except that extraction was performed in ethanol:water (70:30), which is optimal for sulfur containing $\gamma$-glutamyl dipeptides [64]. Replicate samples consisted in independent pools of eight seeds which were ground in liquid nitrogen, and $100 \mathrm{mg}$ of ground tissue was used for extraction. $\gamma$-Glu-S-methylCys and $\gamma$-Glu-Leu standards were from Bachem Americas (Torrance, CA).

\section{RNA extraction}

RNA was extracted using a modified lithium chloride precipitation method [63]. RNA was quantified by spectrophotometry on a NanoDrop 2000 (Thermo Scientific, Wilmington, DE) and its quality evaluated from $\mathrm{A}_{260 / 280}$ ratio and agarose gel electrophoresis. Poly $\mathrm{A}^{+}$RNA was isolated using the Ambion Poly(A)Purist mRNA purification kit (Applied Biosystems, Streetsville, ON). Its quality was analyzed with a 2100 Bioanalyzer (Agilent 
Technologies, Mississauga, ON) at the London Regional Genomics Centre, ON.

\section{cDNA library construction}

Standard and normalized cDNA libraries were prepared for each developmental stage. cDNA was synthesized from $1 \mu \mathrm{g}$ poly $\mathrm{A}^{+}$RNA using the SMART cDNA construction kit (Clontech Laboratories, Mountain View, CA). SMART-amplified cDNA was normalized using the Trimmer-Direct cDNA normalization kit (Evrogen, Moscow, Russia). SfiI-digested cDNA was purified using the QIAquick PCR purification kit (Qiagen, Mississauga, ON). cDNA was size fractionated on a $1 \%$ agarose gel run at $45 \mathrm{~V}$ until the bromophenol blue dye was $2 \mathrm{~cm}$ away from the well, and the band was excised in two fractions corresponding to 0.5 to $1.5 \mathrm{~kb}$ and greater than $1.5 \mathrm{~kb}$. cDNA was extracted using the QIAquick gel extraction kit (Qiagen), and the two fractions were ligated separately to a modified pBluescript II KS+ (Agilent) containing $S f i$ cloning sites. Ligation reactions were purified using the MinElute reaction cleanup kit (Qiagen). The ligation product was transformed into ElectroMAX DH10B T1-phage resistant competent cells (Invitrogen, Burlington, ON).

\section{EST sequencing and analysis}

Culture plates (384-well) were inoculated with a Norgren Systems CP7200 colony picker (Ronceverte, WV). Plasmids were amplified using TempliPhi (GE Healthcare Life Sciences, Baie d'Urfé, QC) and cycle sequenced using Applied Biosystems BigDye chemistry and a BioRAPTR FRD microfluidic workstation (Beckman Coulter Canada, Mississauga, ON) for amplification and sequencing reaction set-up. Completed 384-well sequencing plates were processed with Applied Biosystems 3730xl DNA analyzers. Most clones were sequenced from the 5 ' end using M13 Reverse primer; a small number were also sequenced with the M13-20 primer. EST processing involved quality-trimming, vector-masking, low-complexity masking, and poly-A trimming using custom perl scripts. Assembly was performed with TGICL [65] and the results stored in the FIESTA-2 database at the Plant Biotechnology Institute of the National Research Council of Canada. A total of 30,147 ESTs were assembled into 3,658 contigs and 6,027 singletons. Annotation was done by BLASTx against UniProt Plants version 15 where accessions with uninformative annotations such as "unknown protein", "putative predicted protein", "shotgun sequence from scaffold", etc. had been removed (June 19, 2009) [66]. GO annotations were transferred from the best BLASTx hit to TAIR version 8 (June 8, 2009 ) if the e value was smaller than or equal to $1^{-10}$. Contigs and singletons reported in Figure 5 were verified for the absence of cloning or sequencing artifacts.

\section{RACE and CDNA cloning}

Total RNA from SMARC1N-PN1 (20 mg seed weight) was digested with amplification grade DNase I (Invitrogen). First strand cDNA was synthesized using ThermoScript RT-PCR system from $1 \mu \mathrm{g}$ RNA (Invitrogen). 5' RNA ligase mediated RACE was performed with Ambion FirstChoice RLM-RACE Kit (Applied Biosystems) using Taq DNA polymerase (New England Biolabs, Pickering, ON). 5' RACE gene specific outer (O) and inner (I) primers were the following: for legumin, Leg-O, 5' -TCCGCCACCATAAAGTTCTGT-3' and Leg-I, 5'-CTAACTTGTCCTTGCCCCTCG-3'; and for albumin-2, Alb2-O, 5'-TTACATCAGGAAAGGAATCAGGC-3' and Alb2-I, 5'-TGTTTTGTGACGAGGATAAGGTG-3'. RACE products were either blunted with the Klenow fragment of DNA polymerase I and cloned into the Zero Blunt TOPO vector (Invitrogen) or cloned directly into the pGEM-T Easy vector (Promega, Madison, WI). Full-length cDNAs were cloned by RT-PCR with Pfx50 DNA polymerase (Invitrogen) into the Zero Blunt TOPO vector using the following primers: for legumin, Legumin-F, 5'-ACCAACCCATTCACCACTTC-3' and Legumin-R, 5'-AAGAAAGGCTTGCTAGGATGG-3'; and for albumin-2, Albumin2-F, 5'-AAGCATCCTCAAATCAAATCA-3' and Albumin2-R, 5'AACCAAACCACCCACTTTTA-3'. Multiple sequence alignment and phylogenetic analysis with PHYLIP were performed as previously described [63]. Triticin was used as outgroup.

\section{Protein extraction and purification}

Soluble protein was extracted from mature seed according to VandenBosch et al. [67], except that $50 \mathrm{mM}$ Tris$\mathrm{HCl}, \mathrm{pH} 7.5$ was replaced with $50 \mathrm{mM}$ Tris- $\mathrm{HCl}, \mathrm{pH}$ 8.0. Protein concentration was measured with the BioRad Protein Assay solution and bovine serum albumin as standard. Protein precipitated with saturated ammonium sulfate between 50 to $60 \%(\mathrm{w} / \mathrm{v})$ was dissolved in $50 \mathrm{mM}$ bis-Tris- $\mathrm{HCl}$, pH 6.5 containing $14 \mathrm{mM} 2$-mercaptoethanol and desalted on a PD-10 column (GE Healthcare Life Sciences). The extract was separated by ion exchange chromatography on a HiPrep 16/10 Q FF column, using an ÄKTApurifier system (GE Healthcare Life Sciences). Protein was eluted with a linear gradient of 0 to $0.5 \mathrm{M} \mathrm{NaCl}$. Purified fractions of interest were concentrated using an Amicon Ultra-15 centrifugal filter unit with Ultracel-10 membrane (Millipore, Billerica, MA) prior to size exclusion chromatography on a HiLoad Superdex 75 prep grade column (GE Healthcare Life Sciences) using $50 \mathrm{mM}$ bis-Tris- $\mathrm{HCl}, 150 \mathrm{mM} \mathrm{NaCl}$ containing $14 \mathrm{mM}$ 2-mercaptoethanol as buffer. Proteins were further chromatographed by size exclusion on a Superose 6 10/300 GL column. Molecular weight was determined from a plot of the partition coefficient, $K_{a v}$, 
versus the logarithm of the molecular weight of protein standards. The following proteins were used for calibration: thyroglobulin $(669 \mathrm{kD})$; ferritin $(440 \mathrm{kD})$; and catalase $(232 \mathrm{kD})$.

\section{Protein identification}

To confirm protein and cDNA identity, LC-MS/MS data from 2-D gel spots [11] was used for de novo sequencing with PEAKS Studio v. 4.5 (Bioinformatics Solutions Inc., Waterloo, $\mathrm{ON}$ ) [68] as previously described, and compared to conceptual cDNA translations. Protein fractions eluted from the HiLoad Superdex 75 prep grade column, and 44.0 and $42.7 \mathrm{kD}$ legumin $\alpha$-subunit present in Superose 6 10/300 GL fractions, were separated by SDS-PAGE on $12 \%$ polyacrylamide gels. Bands were excised, digested with trypsin and the resulting peptides were subjected to LC-MS for protein identification. For group 3 late embryogenesis abundant protein, and 44.0 and $42.7 \mathrm{kD}$ legumin $\alpha$-subunits, LC-MS/MS was performed as previously described for 2-D gel spots [11], except that the gradient was lengthened to $90 \mathrm{~min}$. The 44.0 and $42.7 \mathrm{kD}$ legumin $\alpha$-subunits were identified by Mascot search of the assembled EST database, to which the legumin cDNA sequence had been appended, using an in-house server [69]. For the major legumin bands, peptides were analyzed by LC-MS using an Alliance 2690 HPLC and a model LCT orthogonal acceleration time-of-flight mass spectrometer (Waters, Mississauga, ON). Samples were diluted to $100 \mu \mathrm{L}$ with 100:0.1 (v/v) water-formic acid. A $50 \mu \mathrm{L}$ portion was injected into a $100 \mu \mathrm{L}$ loop attached to a 10 port valve (VICI Valco Canada, Brockville, ON) and the valve was switched to permit transfer to a $1 \mathrm{~mm}$ ID $\times 5 \mathrm{~mm} \mathrm{C18}$ PepMap 100 trapping column (Dionex, Bannockburn, IL), using 100:0.1 (v/v) water-formic acid flowing at 0.1 $\mathrm{mL} / \mathrm{min}$ from an auxiliary high pressure pump. After 10 min transfer/washing, the valve was switched to place the trapping column in line with a $1 \mathrm{~mm} \mathrm{ID} \times 150 \mathrm{~mm}$ C18 PepMap 100 analytical column (Dionex) and the peptides were eluted with a gradient of water-acetonitrile-formic acid flowing at $30 \mu \mathrm{L} / \mathrm{min}$. An ACURATE flow splitter (Dionex) was used to reduce the flow of 0.3 $\mathrm{mL} / \mathrm{min}$ from the HPLC to this level. Solvent A was 90:10:0.1 (v/v/v) water-acetonitrile-formic acid and solvent $B$ was 10:90:0.1 water-acetonitrile-formic acid. The gradient conditions were $5 \mathrm{~min}$ at $100 \% \mathrm{~A}$, a linear increase to $40 \%$ B from 5 to $35 \mathrm{~min}$, a 5 min hold at $40 \%$ B followed by a return to $100 \% \mathrm{~A}$ at $45 \mathrm{~min}$ and a 15 min equilibration time. The column effluent was transferred to a Megaflow electrospray probe of the mass spectrometer where the components were ionized and subsequently analyzed. The ion source was operated in positive mode with a capillary voltage of $3 \mathrm{kV}$ with nitrogen as desolvation gas flowing at $250 \mathrm{~L} / \mathrm{h}$ and heated to $250^{\circ} \mathrm{C}$. Mass spectra were acquired from 85 to $1500 \mathrm{~m} / \mathrm{z}$. The cone voltage was switched between 20 and $50 \mathrm{~V}$ at $1.1 \mathrm{sec}$ intervals during data acquisition to permit fragmentation of individual peptides under favorable conditions of chromatographic separation and high peptide concentration. The LC-MS system was operated with MassLynx v. 4.0 and calibrated using a mixture of horse heart myoglobin and trypsinogen. Peak lists were generated from MassLynx raw data files using Mascot Distiller v. 2.2.1 (Matrix Science, Boston, MA). Peptide fragment data for each sample was processed by examining chromatographic peaks for the purity of their $20 \mathrm{~V}$ spectra, combining $50 \mathrm{~V}$ spectra across a suitable peak as representative of fragments of a single peptide and saving the data as a mass vs. intensity text file. These text files for the peptides in a sample were manually combined into a text file in .pkl format representative of the sample. Peptide mass fingerprint data was analyzed against the conceptual translation using PAWS (Digilab, Holliston, MA) and peptide sequence tags derived with Peaks Studio.

\section{Statistical analysis}

$K$-means and hierarchical clustering was performed with GeneSpring GX v. 11.5 (Agilent).

\section{Accession numbers}

Nucleotide sequence data from this article has been deposited in the GenBank database under accession numbers [GenBank ID: GW884178 to GW914324] for seed ESTs; [GenBank ID: HM240256] for legumin; [GenBank ID: HM240257] for albumin-2; [GenBank ID: HM240258] for defensin D1; [GenBank ID: HM240259] for defensin D2; [GenBank ID: HM240260] for albumin1A; [GenBank ID: HM240261] for albumin-1B; [GenBank ID: HM240262] for albumin-1D; [GenBank ID: HM240263] for albumin-1F; [GenBank ID: HM240264] for albumin-1E; [GenBank ID: HM240265] for albumin1C; and [GenBank ID: HM240266] for albumin-1G. Additional amino acid sequence data can be found under accession numbers [UniProt ID: Q41115] for $\alpha$ phaseolin; [UniProt ID: Q43632] for phaseolin encoded by Phs; [UniProt ID: Q8RVX5] for lectin encoded by lec4-B17; [UniProt ID: Q8RVX6] for phytohemagglutinin encoded by pha-E; [UniProt ID: P15231] for leucoagglutinating phytohemagglutinin encoded by $P D L E C 2$; [UniProt ID: Q43628] for phytohemagglutinin; [UniProt ID: Q6J2U4] for $\alpha$-amylase inhibitor-1; [UniProt ID: Q9SMH0] for $\alpha$-amylase inhibitor-like protein; [UniProt ID: Q9SB11] for glycinin A5A4B3 (G. max); [UniProt ID: Q647H1] for arachin 5; [UniProt ID: B5U8K1] for legumin storage protein 2; [UniProt ID: B5U8K2] for legumin storage protein 3; [UniProt ID: Q39921] for glycinin A5A4B3 (G. soja); [UniProt ID: A3KEY8] for 
glycinin A3B4 (G. soja); [UniProt ID: P04347] for glycinin A3B4 (G. $\max$ ); [UniProt ID: Q3HW60] for glycinin G7; [UniProt ID: O24294] for minor small legumin; [UniProt ID: Q43673] for legumin-related high molecular weight polypeptide; [UniProt ID: P05190] for legumin B ( $V . f a b a)$; [UniProt ID: Q41703] for legumin B (V. sativa); [UniProt ID: P05692] for legumin J; [UniProt ID: P11828] for glycinin G3; [UniProt ID: P04776] for glycinin G1; [UniProt ID: P04405] for glycinin G2; [UniProt ID: Q0GM57] for iso-Arah3; [UniProt ID: Q5I6T2] for arachin Ahy-4; [UniProt ID: Q647H2] for arachin Ahy-3; [UniProt ID: B5U8K6] for legumin storage protein 5; [UniProt ID: Q9T0P5] for legumin A (P. sativum); [UniProt ID: Q41702] for legumin A (V. sativa); [UniProt ID: Q99304] for legumin A2; [UniProt ID: Q9SMJ4] for legumin (C. arietinum); [UniProt ID: Q53I54] for legumin-like protein; [UniProt ID: B2CGM6] for triticin; [UniProt ID: Q43680] for seed albumin ( $V$. radiata); [UniProt ID: P08688] for albumin2 (P. sativum); [UniProt ID: Q8W434] for defensin D2 ( $V$. radiata); [UniProt ID: C1K3M7] for defensin ( $V$. unguiculata); [UniProt ID: Q7XZC2] for albumin-1 (P. vulgaris); [UniProt ID: Q39837] for albumin-1 (G. max).

\section{Additional material}

Additional file 1: Free amino acid profiles in developing seeds of
BAT93.
Additional file 2: Percent of ESTs assigned to a Gene Ontology
category per developmental stage (\%).
Additional file 3: Legumin (A) and albumin-2 (B) tryptic peptides
identified by de novo sequencing of LC-MS/MS data; Identification
of purified proteins after size exclusion chromatography: group 3
late embryogenesis abundant protein (C); legumin precursor (D), $\alpha$ -
$-54.8 \mathrm{kD}(\mathrm{E}), \beta-(\mathrm{F})$, and $\alpha--44.0$ and $42.7 \mathrm{kD}(\mathrm{G})$ subunits.

\section{Acknowledgements}

We thank Phillip N. Miklas at the Vegetable and Forage Crop Research Unit, USDA-ARS, for BAT93 seeds, Thomas C. Osborn at the University of Wisconsin in Madison for SMARC1N-PN1 seeds, and Jon Page at the Plant Biotechnology Institute of the National Research Council of Canada for the modified pBluescript vector. We are grateful to staff at the Plant Biotechnology Institute, Darrin Klassen and Donna-Lee Fancy of the DNA Technologies Laboratory for EST sequencing, Dustin Cram and Kannan Vijayan of the Bioinformatics Centre for bioinformatic analysis and Rong Li for advice on CDNA library preparation. We acknowledge the technical help of Rey Interior, at the Advanced Protein Technology Centre, Hospital for Sick Children, with amino acid analysis, and Line Roy, Sylvie Laboissière and Marcos di Falco at the Proteomic Platform, McGill University and Génome Québec Innovation Centre, with proteomic experiments. We appreciate the assistance of staff at the Southern Crop Protection and Food Research Centre, Agriculture and Agri-Food Canada, Deborah Buhlers with field growth, Alex Molnar with preparation of figures and Mark Gijzen for advice on multivariate analyses, and of Steve Karcz at the Saskatoon Research Centre, Agriculture and Agri-Food Canada for access to the Mascot server. This work was supported in part by the Ontario Bean Producers' Marketing Board, the Natural Products Genomics Resource (NAPGEN) consortium, funded by the Plants for Health \& Wellness initiative of the National Research Council of Canada, the Pulse Research Network, funded by the
Agricultural Bioproducts Innovation Program of Agriculture and Agri-Food Canada, and the Ontario Research Fund, Research Excellence Program of the Ontario Ministry of Research and Innovation. FY was supported by the China Scholarship Council.

\section{Author details}

${ }^{1}$ Department of Bioscience and Biotechnology, School of Life Sciences, Sun Yat-sen University, Guangzhou 510275, China. ${ }^{2}$ Agriculture and Agri-Food Canada, Southern Crop Protection and Food Research Centre, 1391 Sandford St., London, ON N5V 4T3 Canada. ${ }^{3}$ National Research Council of Canada, Plant Biotechnology Institute, 110 Gymnasium Place, Saskatoon, SK S7N OW9 Canada. ${ }^{4}$ Department of Biology, University of Western Ontario, London, ON N6A 5B7 Canada.

\section{Authors' contributions}

FY performed most experiments. AP constructed cDNA libraries. RC performed LC-MS analyses. AS developed protocols for, and provided the high throughput Sanger DNA sequencing. SH co-supervised FY and helped draft the manuscript. FM designed the study and wrote the manuscript. All authors read and approved the final manuscript.

Received: 13 December 2010 Accepted: 26 May 2011

Published: 26 May 2011

\section{References}

1. Vitale A, Bollini R: Legume storage proteins. In Seed Development and Germination. Edited by: Kigel J, Galili G. New York: Marcel Dekker; 1995:73-102.

2. Montoya CA, Lallès JP, Beebe $S$, Leterme P: Phaseolin diversity as a possible strategy to improve the nutritional value of common beans (Phaseolus vulgaris). Food Res Int 2010, 43:443-449.

3. Osborn TC, Hartweck LM, Harmsen RH, Vogelzang RD, Kmiecik KA, Bliss FA: Registration of Phaseolus vulgaris genetic stocks with altered seed protein compositions. Crop Sci 2003, 43:1570-1571.

4. Hartweck LM, Cardona C, Osborn TC: Bruchid resistance of common bean lines having an altered seed protein composition. Theor Appl Genet 1997, 95:1018-1023.

5. Blair MW, Prieto S, Diaz LM, Buendia HF, Cardona C: Linkage disequilibrium at the APA insecticidal seed protein locus of common bean (Phaseolus vulgaris L.). BMC Plant Biol 2010, 10:79.

6. Blair MW, Munoz C, Buendia HF, Flower J, Bueno JM, Cardona C: Genetic mapping of microsatellite markers around the arcelin bruchid resistance locus in common bean. Theor Appl Genet 2010, 121:393-402.

7. Zambre M, Goossens A, Cardona C, Van Montagu M, Terryn N, Angenon G: A reproducible genetic transformation system for cultivated Phaseolus acutifolius (tepary bean) and its use to assess the role of arcelins in resistance to the Mexican bean weevil. Theor Appl Genet 2005, 110:914-924.

8. Nishizawa K, Teraishi M, Utsumi S, Ishimoto M: Assessment of the importance of alpha-amylase inhibitor- 2 in bruchid resistance of wild common bean. Theor Appl Genet 2007, 114:755-764.

9. Taylor M, Chapman R, Beyaert R, Hernández-Sebastià C, Marsolais F: Seed storage protein deficiency improves sulfur amino acid content in common bean (Phaseolus vulgaris L.): redirection of sulfur from gammaglutamyl-S-methyl-cysteine. J Agric Food Chem 2008, 56:5647-5654.

10. Padovese R, Kina SM, Barros RMC, Borelli P, Marquez UML: Biological importance of gamma-glutamyl-S-methylcysteine of kidney bean (Phaseolus vulgaris L.). Food Chem 2001, 73:291-297.

11. Marsolais F, Pajak A, Yin F, Taylor M, Gabriel M, Merino DM, Ma V, Kameka A, Vijayan P, Pham H, Huang S, Rivoal J, Bett K, HernándezSebastià C, Liu Q, Bertrand A, Chapman R: Proteomic analysis of common bean seed with storage protein deficiency reveals up-regulation of sulfur-rich proteins and starch and raffinose metabolic enzymes, and down-regulation of the secretory pathway. J Proteomics 2010, 73:1587-1600.

12. McClean PE, Mamidi S, McConnell M, Chikara S, Lee R: Synteny mapping between common bean and soybean reveals extensive blocks of shared loci. BMC Genomics 2010, 11:184.

13. Ramirez M, Graham MA, Blanco-Lopez L, Silvente S, Medrano-Soto A, Blair MW, Hernandez G, Vance CP, Lara M: Sequencing and analysis of common bean ESTs. Building a foundation for functional genomics. Plant Physiol 2005, 137:1211-1227. 
14. Lee J, Feng J, Campbell KB, Scheffler BE, Garrett WM, Thibivilliers S, Stacey G, Naiman DQ, Tucker ML, Pastor-Corrales MA, Cooper B: Quantitative proteomic analysis of bean plants infected by a virulent and avirulent obligate rust fungus. Mol Cell Proteomics 2009, 8:19-31.

15. Thibivilliers S, Joshi T, Campbell KB, Scheffler B, Xu D, Cooper B, Nguyen HT, Stacey G: Generation of Phaseolus vulgaris ESTs and investigation of their regulation upon Uromyces appendiculatus infection. BMC Plant Biol 2009, 9:46.

16. Hanai $L R$, de Campos T, Camargo LE, Benchimol LL, de Souza AP, Melotto M, Carbonell SA, Chioratto AF, Consoli L, Formighieri EF, Siqueira MV, Tsai SM, Vieira ML: Development, characterization, and comparative analysis of polymorphism at common bean SSR loci isolated from genic and genomic sources. Genome 2007, 50:266-277.

17. Melotto M, Monteiro-Vitorello CB, Bruschi AG, Camargo LE: Comparative bioinformatic analysis of genes expressed in common bean (Phaseolus vulgaris L.) seedlings. Genome 2005, 48:562-570.

18. Yang SS, Valdes-Lopez O, Xu WW, Bucciarelli B, Gronwald JW, Hernandez G, Vance CP: Transcript profiling of common bean (Phaseolus vulgaris L.) using the GeneChip soybean genome array: optimizing analysis by masking biased probes. BMC Plant Biol 2010, 10:85.

19. Mensack MM, Fitzgerald VK, Ryan EP, Lewis MR, Thompson HJ, Brick MA: Evaluation of diversity among common beans (Phaseolus vulgaris L.) from two centers of domestication using 'omics' technologies. BMC Genomics 2010, 11:686

20. Hyten DL, Song Q, Fickus EW, Quigley CV, Lim JS, Choi IY, Hwang EY, Pastor-Corrales M, Cregan PB: High-throughput SNP discovery and assay development in common bean. BMC Genomics 2010, 11:475

21. Walbot V, Clutter M, Sussex IM: Reproductive development and embryogeny in Phaseolus. Phytomorphology 1972, 22:59-68.

22. Bobb AJ, Eiben HG, Bustos MM: PvAlf, an embryo-specific acidic transcriptional activator enhances gene expression from phaseolin and phytohemagglutinin promoters. Plant J 1995, 8:331-343.

23. Berardini TZ, Mundodi S, Reiser L, Huala E, Garcia-Hernandez M, Zhang $P$, Mueller LA, Yoon J, Doyle A, Lander G, Moseyko N, Yoo D, Xu I, Zoeckler B, Montoya M, Miller N, Weems D, Rhee SY: Functional annotation of the Arabidopsis genome using controlled vocabularies. Plant Physiol 2004 135:745-755

24. Anthony $J \mathrm{~L}$, Vonder Haar RA, Hall TC: Nucleotide sequence of an aphaseolin gene from Phaseolus vulgaris. Nucleic Acids Res 1990, 18:3396.

25. Kami JA, Gepts P: Phaseolin nucleotide sequence diversity in Phaseolus. I. Intraspecific diversity in Phaseolus vulgaris. Genome 1994, 37:751-757.

26. Lioi L, Sparvoli F, Galasso I, Lanave C, Bollini R: Lectin-related resistance factors against bruchids evolved through a number of duplication events. Theor Appl Genet 2003, 107:814-822.

27. Prescott VE, Campbell PM, Moore A, Mattes J, Rothenberg ME, Foster PS, Higgins TJV, Hogan SP: Transgenic expression of bean a-amylase inhibitor in peas results in altered structure and immunogenicity. $J$ Agric Food Chem 2005, 53:9023-9030.

28. Ishimoto M, Yamada T, Kaga A: Insecticidal activity of an a-amylase inhibitor-like protein resembling a putative precursor of a-amylase inhibitor in the common bean, Phaseolus vulgaris L. Biochim Biophys Acta 1999, 1432:104-112.

29. Voelker TA, Staswick P, Chrispeels MJ: Molecular analysis of two phytohemagglutinin genes and their expression in Phaseolus vulgaris cv. Pinto, a lectin-deficient cultivar of the bean. EMBO J 1986, 5:3075-3082.

30. Mirkov TE, Wahlstrom J, Hagiwara K, Finardi-Filho F, Kjemtrup S, Chrispeels MJ: Evolutionary relationships among proteins in the phytohemagglutinin-arcelin-a-amylase inhibitor family of the common bean and its relatives. Plant Mol Biol 1994, 26:1103-1113.

31. Moore JG, Fuchs CA, Hata YS, Hicklin DJ, Colucci G, Chrispeels MJ, Feldman M: A new lectin in red kidney beans called PvFRIL stimulates proliferation of NIH 3T3 cells expressing the Flt3 receptor. Biochim Biophys Acta 2000, 1475:216-224.

32. Muhling M, Gilroy J, Croy RRD: Legumin proteins from seeds of Phaseolus vulgaris L. J Plant Physiol 1997, 150:489-492.

33. Yan YS, Lin XD, Zhang YS, Wang L, Wu K, Huang SZ: Isolation of peanut genes encoding arachins and conglutins by expressed sequence tags. Plant Sci 2005, 169:439-445.

34. Bäumlein H, Wobus U, Pustell J, Kafatos FC: The legumin gene family: structure of a B type gene of Vicia faba and a possible legumin gene specific regulatory element. Nucleic Acids Res 1986, 14:2707-2720.
35. Beilinson V, Chen Z, Shoemaker C, Fischer L, Goldberg B, Nielsen C: Genomic organization of glycinin genes in soybean. Theor Appl Genet 2002, 104:1132-1140

36. Dam $\mathrm{S}$, Laursen BS, Ornfelt $J H$, Jochimsen B, Staerfeldt $H H$, Friis $C$, Nielsen $K$, Goffard N, Besenbacher S, Krusell L, Sato S, Tabata S, Thogersen IB, Enghild JJ, Stougaard J: The proteome of seed development in the model legume Lotus japonicus. Plant Physiol 2009, 149:1325-1340.

37. Domoney C, Casey R: Storage protein precursor polypeptides in cotyledons of Pisum sativum L. Identification of, and isolation of a cDNA clone for, an 80 000-M $M_{r}$ legumin-related polypeptide. Eur J Biochem 1984, 139:321-327.

38. Heim $U$, Bäumlein $H$, Wobus $U$ : The legumin gene family: a reconstructed Vicia faba legumin gene encoding a high-molecular-weight subunit is related to type B genes. Plant Mol Biol 1994, 25:131-135.

39. Higgins TJV, Beach LR, Spencer D, Chandler PM, Randall PJ, Blagrove RJ, Kortt AA, Guthrie RE: CDNA and protein sequence of a major pea seed albumin (PA $2: \mathrm{M}_{\mathrm{r}} \approx 26$ 000). Plant Mol Biol 1987, 8:37-45.

40. Gaur V, Qureshi IA, Singh A, Chanana V, Salunke DM: Crystal structure and functional insights of hemopexin fold protein from grass pea. Plant Physiol 2010, 152:1842-1850.

41. Games PD, dos Santos IS, Mello EO, Diz MSS, Carvalho AO, de SouzaFilho GA, Da Cunha M, Vasconcelos IM, dos S, Ferreira B, Gomes VM: Isolation, characterization and cloning of a cDNA encoding a new antifungal defensin from Phaseolus vulgaris L. seeds. Peptides 2008, 29:2090-2100.

42. Lin KF, Lee TR, Tsai PH, Hsu MP, Chen CS, Lyu PC: Structure-based protein engineering for a-amylase inhibitory activity of plant defensin. Proteins 2007, 68:530-540.

43. Louis S, Delobel B, Gressent F, Rahioui I, Quillien L, Vallier A, Rahbé Y: Molecular and biological screening for insect-toxic seed albumins from four legume species. Plant Sci 2004, 167:705-714.

44. Watanabe Y, Barbashov SF, Komatsu S, Hemmings AM, Miyagi M, Tsunasawa S, Hirano H: A peptide that stimulates phosphorylation of the plant insulin-binding protein. Isolation, primary structure and CDNA cloning. Eur J Biochem 1994, 224:167-172.

45. Higgins TJ, Chandler PM, Randall PJ, Spencer D, Beach LR, Blagrove RJ, Kortt AA, Inglis AS: Gene structure, protein structure, and regulation of the synthesis of a sulfur-rich protein in pea seeds. J Biol Chem 1986, 261:11124-11130.

46. Yamazaki T, Takaoka M, Katoh E, Hanada K, Sakita M, Sakata K, Nishiuchi Y, Hirano $\mathrm{H}$ : A possible physiological function and the tertiary structure of a 4-kDa peptide in legumes. Eur J Biochem 2003, 270:1269-1276.

47. Jouvensal L, Quillien L, Ferrasson E, Rahbé Y, Guéguen J, Vovelle F: PA1b, an insecticidal protein extracted from pea seeds (Pisum sativum): ${ }^{1} \mathrm{H}-2-\mathrm{D}$ NMR study and molecular modeling. Biochemistry 2003, 42:11915-11923.

48. Fait A, Angelovici R, Less H, Ohad I, Urbanczyk-Wochniak E, Fernie AR, Galili G: Arabidopsis seed development and germination is associated with temporally distinct metabolic switches. Plant Physiol 2006, 142:839-854

49. Yi H, Ravilious GE, Galant A, Krishnan HB, Jez JM: From sulfur to homoglutathione: thiol metabolism in soybean. Amino Acids 2010, 39:963-978.

50. Tan Q, Zhang L, Grant J, Cooper P, Tegeder M: Increased phloem transport of S-methylmethionine positively affects sulfur and nitrogen metabolism and seed development in pea plants. Plant Physiol 2010, 154:1886-1896.

51. Anderson JW, Fitzgerald MA: Physiological and metabolic origin of sulphur for the synthesis of seed storage proteins. J Plant Physiol 2001, 158:447-456.

52. Sunarpi, Anderson JW: Allocation of S in generative growth of soybean Plant Physiol 1997, 114:687-693.

53. Zuber H, Davidian JC, Aubert G, Aime D, Belghazi M, Lugan R, Heintz D, Wirtz M, Hell R, Thompson R, Gallardo K: The seed composition of Arabidopsis mutants for the group 3 sulfate transporters indicates a role in sulfate translocation within developing seeds. Plant Physiol 2010, 154:913-926

54. Zuber H, Davidian JC, Wirtz M, Hell R, Belghazi M, Thompson R, Gallardo K: Sultr4; 1 mutant seeds of Arabidopsis have an enhanced sulphate content and modified proteome suggesting metabolic adaptations to altered sulphate compartmentalization. BMC Plant Biol 2010, 10:78. 
55. Ranocha P, McNeil SD, Ziemak MJ, Li CJ, Tarczynski MC, Hanson AD: The S-methylmethionine cycle in angiosperms: ubiquity, antiquity and activity. Plant J 2001, 25:575-584.

56. Momma T, Negoro T, Hirano H, Matsumoto A, Udaka K, Fukazawa C: Glycinin $\mathrm{A}_{5} \mathrm{~A}_{4} \mathrm{~B}_{3}$ mRNA: cDNA cloning and nucleotide sequencing of a splitting storage protein subunit of soybean. Eur J Biochem 1985, 149:491-496.

57. Kinney AJ, Jung R, Herman EM: Cosuppression of the alpha subunits of beta-conglycinin in transgenic soybean seeds induces the formation of endoplasmic reticulum-derived protein bodies. Plant Cell 2001, 13:1165-1178

58. Freitas RL, Teixeira AR, Ferreira RB: Characterization of the proteins from Vigna unguiculata seeds. J Agric Food Chem 2004, 52:1682-1687.

59. Bourgeois M, Jacquin F, Savois V, Sommerer N, Labas V, Henry C, Burstin J: Dissecting the proteome of pea mature seeds reveals the phenotypic plasticity of seed protein composition. Proteomics 2009, 9:254-271.

60. Schmidt H, Gelhaus C, Latendorf T, Nebendahl M, Petersen A, Krause S, Leippe M, Becker WM, Janssen O: 2-D DIGE analysis of the proteome of extracts from peanut variants reveals striking differences in major allergen contents. Proteomics 2009, 9:3507-3521.

61. Nodari RO, Tsai SM, Guzman P, Gilbertson RL, Gepts P: Toward an integrated linkage map of common bean. III. Mapping genetic factors controlling host-bacteria interactions. Genetics 1993, 134:341-350.

62. Kami J, Poncet V, Geffroy V, Gepts P: Development of four phylogenetically-arrayed BAC libraries and sequence of the APA locus in Phaseolus vulgaris. Theor Appl Genet 2006, 112:987-998.

63. Bruneau L, Chapman R, Marsolais F: Co-occurrence of both L-asparaginase subtypes in Arabidopsis: At3g16150 encodes a K $\mathrm{K}^{+}$- dependent Lasparaginase. Planta 2006, 224:668-679.

64. Arias M, Simo C, Ortiz LT, de los Mozos-Pascual M, Barbas C, Cifuentes A: Detection and quantitation of a bioactive compound in Vicia narbonensis L. seeds by capillary electrophoresis-mass spectrometry: a comparative study with UV detection. Electrophoresis 2005, 26:2351-2359.

65. Pertea G, Huang X, Liang F, Antonescu V, Sultana R, Karamycheva S, Lee Y White J, Cheung F, Parvizi B, Tsai J, Quackenbush J: TIGR Gene Indices clustering tools (TGICL): a software system for fast clustering of large EST datasets. Bioinformatics 2003, 19:651-652.

66. Schneider M, Lane L, Boutet E, Lieberherr D, Tognolli M, Bougueleret L, Bairoch A: The UniProtKB/Swiss-Prot knowledgebase and its plant proteome annotation program. J Proteomics 2009, 72:567-573.

67. VandenBosch KA, Bradley DJ, Knox JP, Perotto S, Butcher GW, Brewin NJ: Common components of the infection thread matrix and the intercellular space identified by immunocytochemical analysis of pea nodules and uninfected roots. EMBO J 1989, 8:335-342.

68. Ma B, Zhang K, Hendrie C, Liang C, Li M, Doherty-Kirby A, Lajoie G: PEAKS: powerful software for peptide de novo sequencing by tandem mass spectrometry. Rapid Commun Mass Spectrom 2003, 17:2337-2342.

69. Perkins DN, Pappin DJ, Creasy DM, Cottrell JS: Probability-based protein identification by searching sequence databases using mass spectrometry data. Electrophoresis 1999, 20:3551-3567.

doi:10.1186/1471-2164-12-268

Cite this article as: Yin et al:: Analysis of common bean expressed sequence tags identifies sulfur metabolic pathways active in seed and sulfur-rich proteins highly expressed in the absence of phaseolin and major lectins. BMC Genomics 2011 12:268.

\section{Submit your next manuscript to BioMed Central and take full advantage of:}

- Convenient online submission

- Thorough peer review

- No space constraints or color figure charges

- Immediate publication on acceptance

- Inclusion in PubMed, CAS, Scopus and Google Scholar

- Research which is freely available for redistribution

Submit your manuscript at www.biomedcentral.com/submit
Biomed Central 